\title{
Microstructures and Mechanical Properties of Friction Welded Joint Using a 5052 Aluminum Alloy Small Diameter Rod ${ }^{* 1}$
}

\author{
Yuki Asano ${ }^{1, * 2}$, Mitsuteru Nomoto ${ }^{2, * 3}$, Masakatsu Maeda ${ }^{2}$ and Kazuyoshi Katoh ${ }^{2}$ \\ ${ }^{1}$ Graduate School of Industrial Technology, Nihon University, Narashino 275-8575, Japan \\ ${ }^{2}$ College of Industrial Technology, Nihon University, Narashino 275-8575, Japan
}

A 5052-H34 aluminum alloy rod having a diameter of $5 \mathrm{~mm}$ was friction-welded using a conventional automatic friction welder. The effect of welding conditions on the microstructure and mechanical properties of the welded joints were investigated. The total loss of mechanical strength of welded joints increases when increasing both the rotational speed and friction time. In addition,the total loss was negligibly low when the welding condition was submitted to $\mathrm{N}=6000 \mathrm{rpm}$ and $\mathrm{t} 1=1 \mathrm{~s}$. The welded joints showed a symmetrical macrostructure with respect to the weld interface and rotational axis. A layer with fine-grained microstructure was formed at the weld interface. The layer grew thicker by increasing both the rotational speed and friction time. The heat-affected zone was formed around the fine-grained layer. It tends to be larger with an increase in both the rotational speed and friction time. The softened area of the joints reached approximately $8 \mathrm{~mm}$ from the weld interface. In addition, the weld interface was cured under conditions of $\mathrm{N}=6000 \mathrm{rpm}$ and $\mathrm{t} 1=1 \mathrm{~s}$. The highest tensile strength of thin diameter joints was $209 \mathrm{MPa}$, which was obtained under conditions of $\mathrm{N}=6000 \mathrm{rpm}$ and $\mathrm{t} 1=3 \mathrm{~s}$. Its joint efficiency reached $80 \%$ of that of the base metal. [doi:10.2320/matertrans.L-M2017815]

(Received October 3, 2016; Accepted March 31, 2017; Published June 25, 2017)

Keywords: friction welding, small diameter rod, 5052 aluminum alloy, microstructures, mechanical properties

\section{Introduction}

Friction welding is a joining method that uses the heat generated in the friction surface during rotary sliding. This method presents a good workability, excellent reproducibility, and other advantages such as easy joining on dissimilar materials that cannot be joined by fusion welding, and it does not require a special joining atmosphere. Owing to such advantages, friction welding has been adapted in several fields such as the automotive industry and the electrical equipment industry, providing many research studies ${ }^{1,2)}$ and applications ${ }^{3)}$. In addition, there are reports using resin materials ${ }^{4)}$ as well as metal materials, and it is expected that the range of use will be expanded in the future.

Many of these studies are related to friction welding of rod diameters around 10-30 mm. However, most of the latest devices and structures are developed demanding the use of lightweight and downsized solutions, thereby requiring studies regarding friction welding in pieces having smaller dimensions. There are not many reports concerning friction welding on small-diameter rods ${ }^{5}$.

Moreover, a common problem in friction welding of small-diameter rods is the limited size of the friction surface and the stiffness of the rod. With a small friction surface, the frictional heating is not enough to fabricate the joint, thereby making it difficult to fabricate fine joints via friction welding. The amount of heat generated by friction is determined from the following eqs. $(1)^{6)}$ and $(2)^{7)}$.

$$
\mathrm{q}_{i f}=2 \pi N_{i} T_{i} \eta
$$

\footnotetext{
${ }^{* 1}$ This Paper was Originally Published in Japanese in J. JILM 65 (2015) 485-491.

${ }^{* 2}$ Graduate Student, Nihon University, Present address: JFE SEKKEI LTD., Tokyo 111-0051, Japan

${ }^{* 3}$ Corresponding author, E-mail: nomoto.mitsuteru@nihon-u.ac.jp
}

$$
T_{i}=\frac{2}{3} \pi \mu P_{1} r^{3}
$$

where $q_{i f}$ is the amount of heat generation $(\mathrm{kJ} / \mathrm{s}), N_{i}$ is the number of revolutions (rps), $T_{i}$ is the friction torque $(\mathrm{Nm}), \eta$ is the conversion efficiency to heat, $\mu$ is the dynamic friction coefficient, $P_{1}$ is the friction pressure (MPa), and $r$ is the rod radius $(\mathrm{m})$.

Therefore, considering that a uniform frictional pressure is exerted on the friction surface with the same rotational speed and friction torque, if the material diameter is reduced to half, the heating generation is reduced by eight times. With this, obtaining a sufficient amount of heat in the junction will be impossible unless the rotational speed or the friction pressure accordingly increases. However, to provide such high friction pressure, the possibility of buckling will be higher due to the limited rigidity of the compressed rod. Also, a high rotational speed may change the flow of the ambient gas near the rotating rod. Thus, there will be a difference in the cooling speed between the rotating and fixed sides. Furthermore, due to the limited heat capacity of the material on reduced cross-sectional areas, the cooling rate is also limited. Thus, the friction welded joint for small-diameter rods will be different to that of large-diameter rods.

We previously examined the mechanical behavior of friction-welding joints using high-strength (2024 aluminum alloy ${ }^{8)}$ ) and medium-strength (5056 aluminum alloy ${ }^{5)}$ ) small-diameter rods. However, the results were not reported due to phenomena such as the ones described above concerning the mechanical properties, joint heating rate and cooling rate effects at the friction weld.

This study was performed by considering the friction-welding of a 5052 aluminum alloy with a small-diameter rod $(5 \mathrm{~mm})$. The difference of rotational speed and friction time of the frictional process was considered regarding their effects on the structures and mechanical properties of the joint.

Furthermore, the friction-welding phenomena and me- 
chanical properties were discussed by comparison of joints with the same material but with rod diameters of $20 \mathrm{~mm}$.

\section{Experimental Method and Materials}

The rods were machined from a 5052-H34 aluminum alloy to a $5 \mathrm{~mm}$ diameter and $40 \mathrm{~mm}$ length. The surface was degreased before the friction-welding process. The chemical composition and mechanical properties of the base metal are shown in Tables 1 and 2, respectively. Friction-welding was performed using a full automatic micro friction welding machine under the conditions shown in Table 3. Such conditions were selected considering past experimental results and preliminary experiments ${ }^{5,8)}$. The appearance of the friction-welding joint, the macro- and microstructure and the hardness (testing load $2.9 \mathrm{~N}$; load holding time $15 \mathrm{~s}$ ) were evaluated. The tensile tests were run according to standard JIS No.2 (removed burr) at room temperature.

Also, to compare the influence of the rod diameter $(5 \mathrm{~mm}$ vs. $20 \mathrm{~mm}$ ) on the final properties, the tests considered the same friction-welding conditions that those stated in Table 3. However, the rotational speed for the different rod diameters, peripheral speed was the speed shown in Table 3 to be identical. Also, the large-diameter joints were tested concerning the mechanical properties evaluation in a similar way, but considering the testing shape conforming to JIS No.10 (diameter $12.5 \mathrm{~mm}$ ) specifications.

For the experiment, two types of friction-welding machines were considered, as described above. The friction-welding phenomenon was different due to the friction-welding machine influence. So, the friction-welding temperatures were different for each case. In this paper, the overhang of the from the chuck, and sine of the chuck did not discussed. The length of overhang from the rigidity of the material, the overhang of $\varphi 5$ was $5 \mathrm{~mm}$. The overhang of $\varphi 20$ was $15 \mathrm{~mm}$.

The temperature measurement was done using a type $\mathrm{K}$

Table 1 Chemical compositions of base metal. (mass\%)

\begin{tabular}{cccccccccc}
\hline Diameter & $\mathrm{Si}$ & $\mathrm{Fe}$ & $\mathrm{Cu}$ & $\mathrm{Mn}$ & $\mathrm{Mg}$ & $\mathrm{Cr}$ & $\mathrm{Zn}$ & $\mathrm{Ti}$ & $\mathrm{Al}$ \\
\hline$\varphi 5 \mathrm{~mm}$ & 0.06 & 0.16 & 0.02 & 0.03 & 2.6 & 0.17 & 0.30 & - & Bal. \\
\hline$\varphi 20 \mathrm{~mm}$ & 0.05 & 0.15 & 0.01 & 0.02 & 2.48 & 0.22 & 0.00 & 0.01 & Bal. \\
\hline
\end{tabular}

Table 2 Mechanical properties of base metal.

\begin{tabular}{cccc}
\hline Diameter $(\mathrm{mm})$ & Tensile strength $(\mathrm{MPa})$ & Elongation $(\%)$ & Hardness (HV0.3) \\
\hline$\varphi 5$ & 265 & 3.7 & 87.3 \\
\hline$\varphi 20$ & 270 & 9.1 & 87.7 \\
\hline
\end{tabular}

Table 3 Friction welding conditions.

\begin{tabular}{lcccc}
\hline Diameter & $\mathrm{d}$ & $(\mathrm{mm})$ & $\varphi 5$ & $\varphi 20$ \\
\hline Rotational speed & $\mathrm{N}$ & $(\mathrm{rpm})$ & $6000,8000,10000$ & $1500,2000,2500$ \\
\hline Friction pressure & $\mathrm{P}_{1}$ & $(\mathrm{MPa})$ & 20 \\
\hline Friction time & $\mathrm{t}_{1}$ & $(\mathrm{~s})$ & $1,2,3$ \\
\hline Upset pressure & $\mathrm{P}_{2}$ & $(\mathrm{MPa})$ & 40 \\
\hline Upset time & $\mathrm{t}_{2}$ & $(\mathrm{~s})$ & 5 \\
\hline
\end{tabular}

thermocouple (wire diameter $0.3 \mathrm{~mm}$ ). The insert positions of the thermocouple were $1 \mathrm{~mm}$ from the friction interface, $3 \mathrm{~mm}$ and $5 \mathrm{~mm}$, being aligned with the axis of the FS (Fixed side).

\section{Result and Discussion}

\subsection{Appearance and total upset}

The appearance of the friction-welding joints is shown Fig. 1. RS (Rotating side) in the figure indicates rotating side, and FS indicates the fixed side. In the Fig. 1(a), burrs generated in the small-diameter joint increased with the rotational speed and friction time. Curly burrs did not appear for this rod in the 5056 aluminum alloy ${ }^{5}$.

For the small-diameter joints with the $5 \mathrm{~mm}$ rod, the length of the protrusive end was lower when the rigidity at friction-welding was reduced. However, a misalignment of the axis was observed at the friction welded joint at $\mathrm{N}=6000 \mathrm{rpm}$, regardless of the friction time. This misalignment of the axis disappeared with the increase of the rotational speed. It was assumed that the rotational speed increase prevented the misalignment of the axis due to the higher centripetal force (rotating stiffness). Also, there is a tendency that the burrs of the FS are large compared to the RS when increasing the rota-
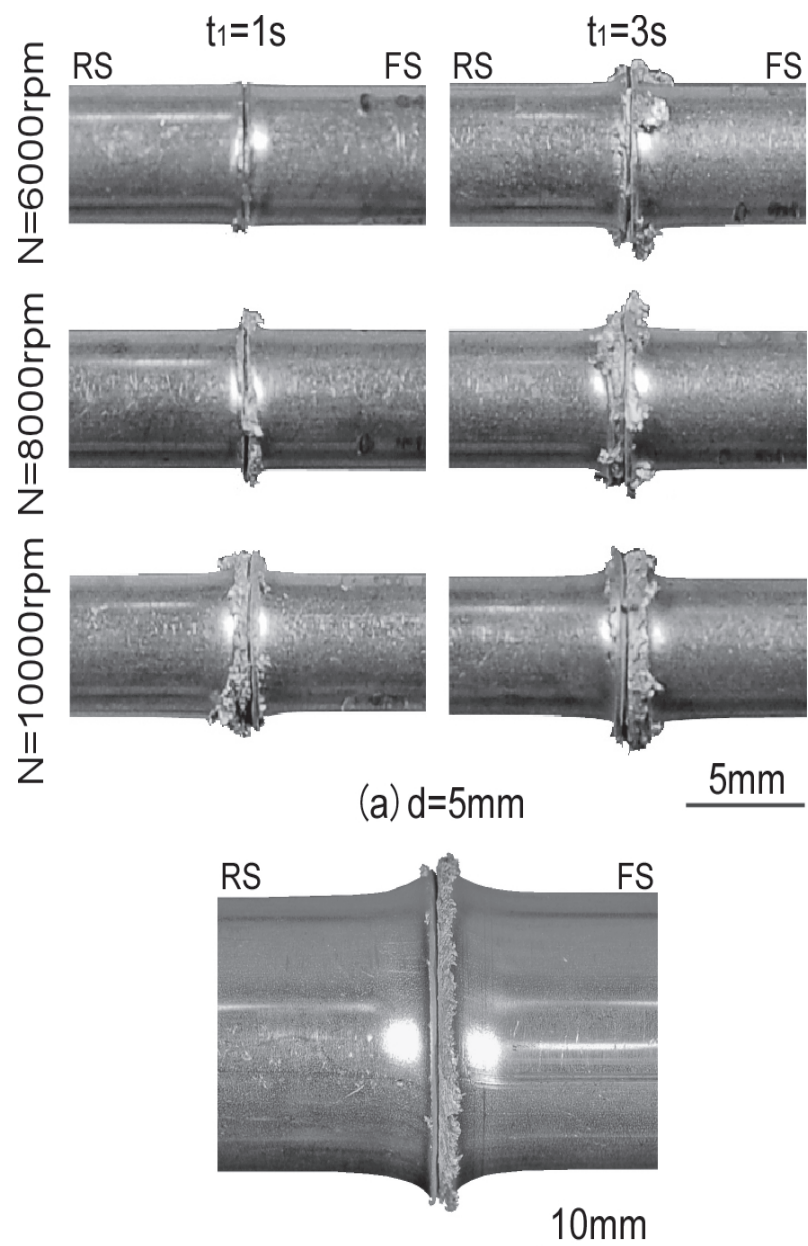

(b) $d=20 \mathrm{~mm}$

Fig. 1 (a) Appearances of the joint of thin $(\varphi 5 \mathrm{~mm})$ rods welded under various conditions, (b) thick $(\varphi 20 \mathrm{~mm})$ rods welded under condition of $\mathrm{N}=$ $2500 \mathrm{rpm}, \mathrm{t} 1=3 \mathrm{~s}$. 
tional speed. The occurrence of burrs tends to be large on the FS can be considered as a variation using this apparatus. This was the same for large-diameter friction-welding joints, as shown in Fig. 1(b). Furthermore, the number of burrs and the misalignment was not observed, highlighting the difference on rod stiffness.

Figure 2 shows the change of the upset in the friction-welding. Both upsets for the small-diameter and large-diameter rods allow the friction process to be adjusted with the rotational speed. In addition, as shown in Fig. 2(b), the beginning of friction deformation process of friction welding was slightly delayed for the large-diameter rod in comparison to the small-diameter one. This burn-off length changes in the axial direction and is equivalent to the number of generated burrs. Thus, the burr volume obtained depends on the burn-off length and the rod diameter. For small-diameter joints, the volume was between 4 and $20 \mathrm{~mm}^{3}$ during $3 \mathrm{~s}$ of friction time, while for the large-diameter joints it was between 100 and $280 \mathrm{~mm}^{3}$.

The upset extension rapidly increased during the upset process by increasing the pressure. The increase rate was higher for the large-diameter joint compared to the small-diameter joint, as shown in Fig. 2(b). Concerning temperature measurements, which will be described later, the friction process

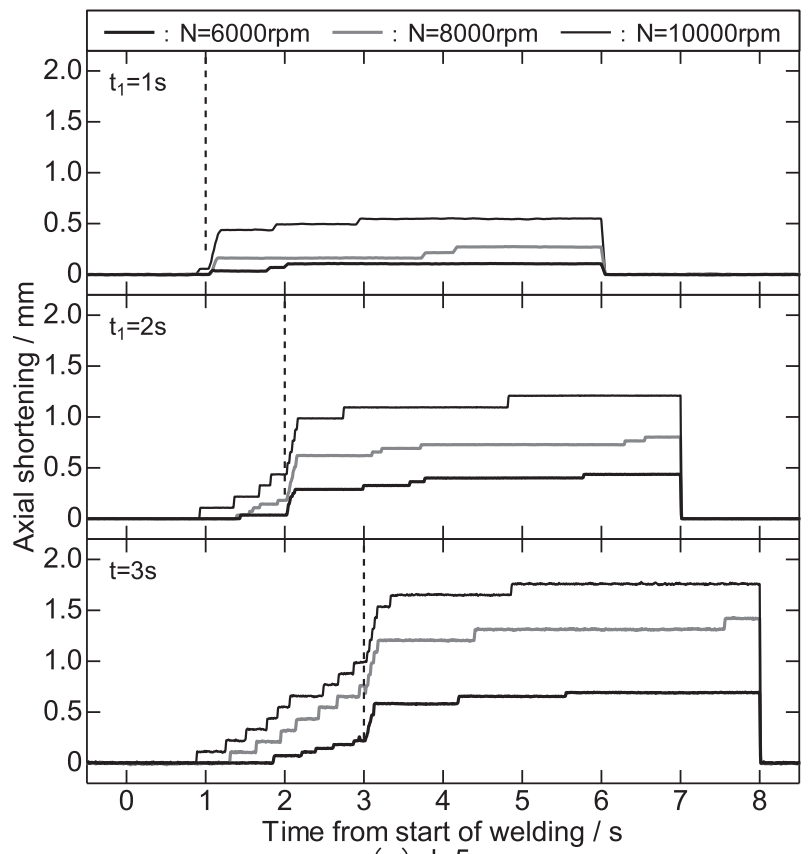

(a) $\mathrm{d}=5 \mathrm{~mm}$

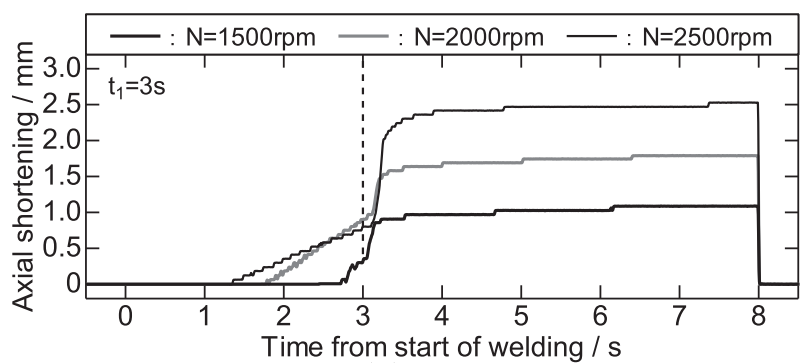

(b) $d=20 \mathrm{~mm}$

Fig. 2 Axial shortening behaviors during friction welding under various conditions. (a) The behaviors of thin $(\varphi 5 \mathrm{~mm})$ rods, (b) thick $(\varphi 20 \mathrm{~mm})$ rods. is due to the temperature distribution at the weld interface. The range of temperature related to the small-diameter joints was narrower than that for the large-diameter joints.

Figure 3 shows the upset and burn-off lengths from the friction process of Fig. 2. The total upset was determined as the difference between the total length of the joint and sum of the total length of the specimen before welding. The total upset correlates with the number of burrs; hence, it increases with an increase in the rotational speed and friction time. The total upset for large-diameter joints showed high values compared to the small-diameter joints when $\mathrm{t} 1$ was higher than $2 \mathrm{~s}$. It is presumed that this is due to the difference in the temperature distribution along the axial direction, as described above. In addition, the total upset under the welding condition of $\mathrm{N}=6000 \mathrm{rpm}$ and $\mathrm{t} 1=1 \mathrm{~s}$ for the small-diameter welding joint, and $\mathrm{N}=1500-2000 \mathrm{rpm}$ during $\mathrm{t} 1=1-2 \mathrm{~s}$ for the large-diameter welding joint could not be observed. The suspect is that these welding conditions produce a low friction pressure compared to other conditions. Also, the generation of heat was low with a short friction time. Therefore, the deformation due to the thermal softening did not occur at the friction surface vicinity. The burn-off length difference was small regarding the diameter influence. The upset length of large-diameter joints was found to be high in proportion to the rotational speed. This is attributed to the difference in the temperature distribution in the axial direction during the upset process and to the restricted heat capacity in the small-diameter joint, as commented before.

\subsection{Temperature change during friction welding}

Figure 4 shows the temperature evolution during the friction-welding process. The temperature at $1 \mathrm{~mm}$ from the friction surface regardless of the rod diameter showed a rapid temperature rise with the start of the friction action, reaching

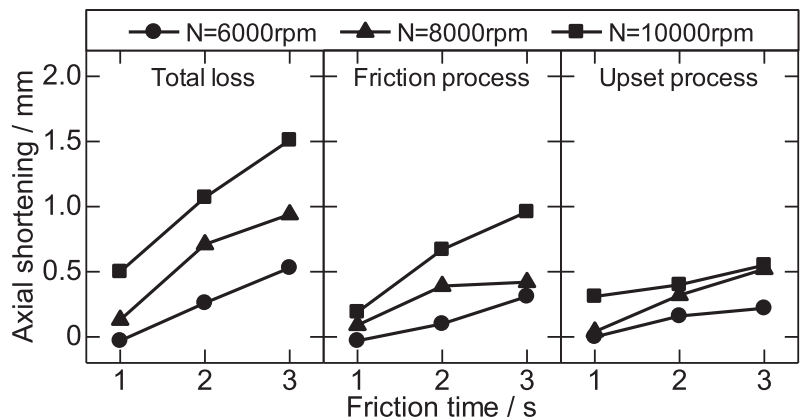

(a) $d=5 \mathrm{~mm}$

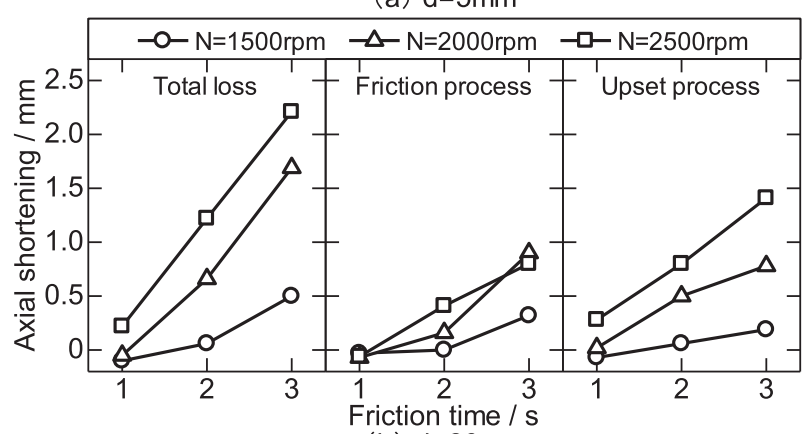

(b) $\mathrm{d}=20 \mathrm{~mm}$

Fig. 3 Relation between friction time and axial shortening for (a) thin $(\varphi 5 \mathrm{~mm})$ rods, (b) thick $(\varphi 20 \mathrm{~mm})$ rods 


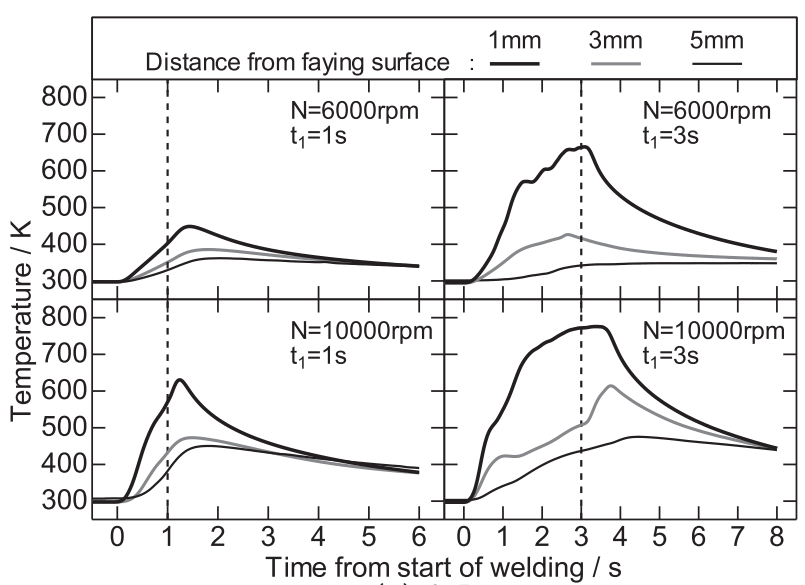

(a) $d=5 \mathrm{~mm}$

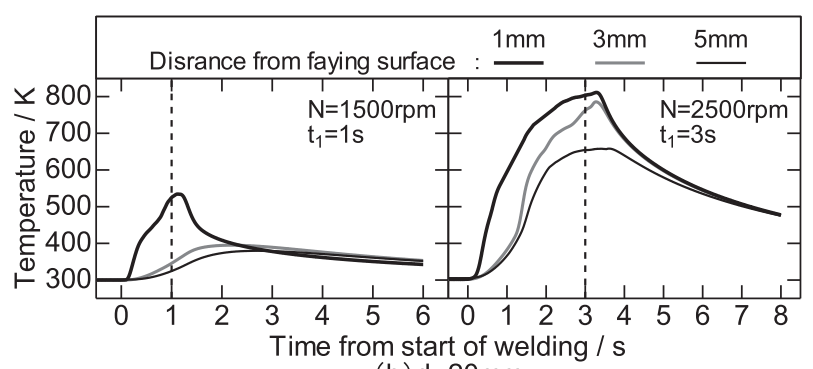

(b) $d=20 \mathrm{~mm}$

Fig. 4 Temperature-time histories during welding under various conditions. (a) The case of thin $(\varphi 5 \mathrm{~mm})$ rods, (b) thick $(\varphi 20 \mathrm{~mm})$ rods.

a maximum temperature value after the friction-welding process.

The maximum temperature was obtained slightly faster for the large-diameter joint compared to the small-diameter joint. This is due to the performance of the friction-welding machine, which considers the time until the main shaft stops. Also, the measurement position of the maximum temperature was lower along the distance from the friction-welding surface regardless of the rod diameter. Its elevated temperature change rate was reduced. Regarding the temperature variations at different positions from the joint surface during $3 \mathrm{~s}$ of friction time, for the small-diameter rod, the temperature was between $200-250 \mathrm{~K}$ at $1 \mathrm{~mm}$ and $260-320 \mathrm{~K}$ at $5 \mathrm{~mm}$. For the large-diameter joint, it was approximately $40 \mathrm{~K}$ at $5 \mathrm{~mm}$ and $100-150 \mathrm{~K}$ at $3 \mathrm{~mm}$, thus, the temperature changes in the axial direction were lower for the large-diameter rod. With these temperature differences and considering the equation of the frictional heat amount in eqs. (1) and (2), the large-diameter rod produces 16 times more frictional heat than the small-diameter joint. However, part of the friction heat is consumed generating the burr and the joints heat capacity depend on the rod diameter, so such difference would be probably lower.

Figure 5 shows the results of the maximum temperature evolution versus time. The maximum temperature produces small differences with the rod diameter during long friction times, and a high temperature was observed for the large-diameter joint during a short friction time. In addition, the maximum temperature obtained when increasing the rotational speed in the small-diameter joint was observed at $\mathrm{N}=$ $8000 \mathrm{rpm}$

The temperature of the rotating side could not be mea-

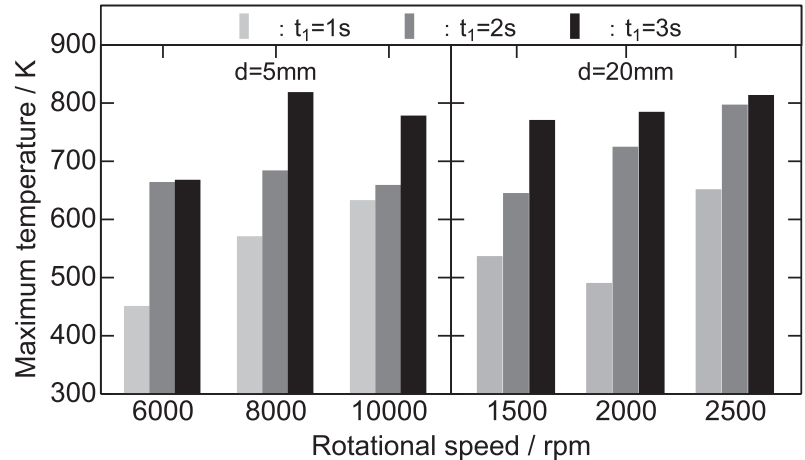

Fig. 5 Relation between rotational speed and maximum temperature of welding process.

sured, but the heat generated in the friction surface could affect the forced air-cooled by the high-speed rotation of the main shaft, increasing when it is transmitted to the shaft direction in the case of $\mathrm{N}=10000 \mathrm{rpm}$. For the joint at $\mathrm{N}=$ $8000 \mathrm{rpm}$ the peak temperature was lower compared to $\mathrm{N}=$ $10000 \mathrm{rpm}$.

\subsection{Macrostructures and microstructures}

Figure 6 shows the cross-section macrostructure of the friction-welded joint. There is a symmetrical structure in the weld interface close to the rotational axis, regardless of the rod diameter. In the center of the friction weld, some altered structures similar to central convex-lens were observed. Similar macrostructures were observed in other studies related to aluminum friction-welding joints of $15-20 \mathrm{~mm}^{9-11)}$. The heat-affected zone of the outer peripheral portion exhibited a concave-lens shape. The regions with these structures were expanded by increasing the revolution speed and the friction time. For small-diameter joints, the heat-affected zones were different, as shown in Fig. 6(a). The appearance was similar to that of 5056 aluminum alloys with small-diameter joints ${ }^{5)}$. The large-diameter joint was the center of the constricted convex shape, as shown in a representative example in Fig. 6(b). The heat affected zone of the peripheral portion is independent of the rod diameter. Concave shapes are considered to be linked to burr formation.

Figure 7 shows the microstructure of the center at the weld interface from small-diameter joints. The microstructure showed a non-defined fine structure in the axial direction of the fibrous direction with a heterogeneous appearance ${ }^{10)}$. The axial center showed some stretched fine structure about 5-10 $\mu \mathrm{m}$ approximately in the axial and perpendicular direction. Furthermore, friction-welding interface was clearly observed mechanical mixing structure ${ }^{12)}$. The outside of the joints exhibited a deformed fibrous structure in the direction of the burr generation. The width of the fine microstructure increased with the revolution speed and friction time. In addition, joint defects (black part in the figure) were observed in the weld interface at low revolution speed. Although not included here, the large-diameter joints also showed a similar appearance to that of the small-diameter joint despite the fact that the weld defects did not appear in all cases. 

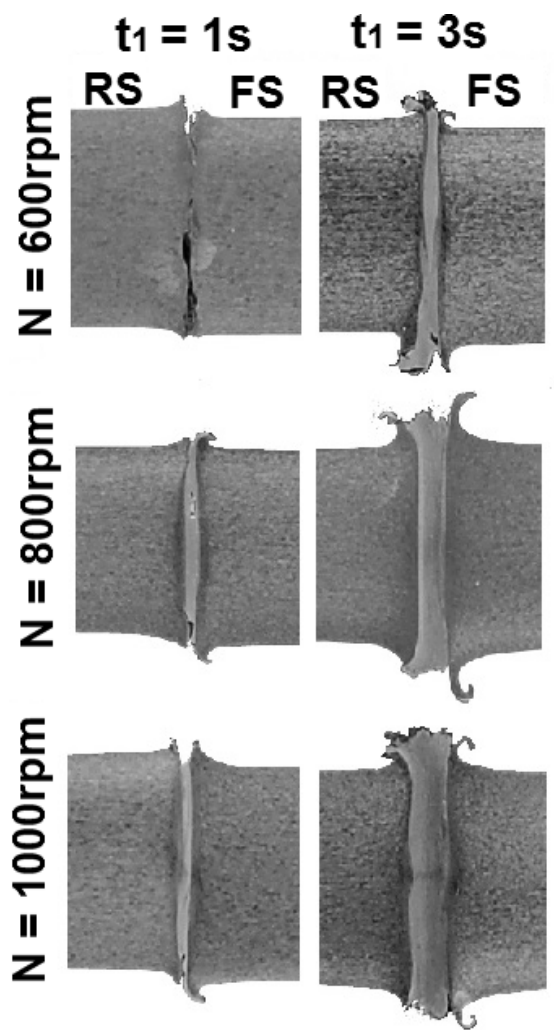

(a) $d=5 \mathrm{~mm} \quad \underline{2 m m}$

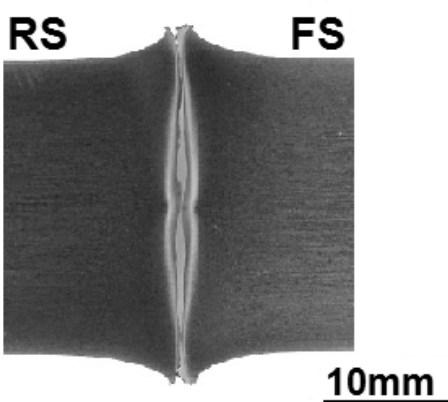

(b) $\mathrm{d}=20 \mathrm{~mm}$

Fig. 6 (a) Macrostructures of the joint of thin $(\varphi 5 \mathrm{~mm})$ rods welded under various conditions, (b) thick $(\varphi 20 \mathrm{~mm})$ rods welded under condition of $\mathrm{N}=2500 \mathrm{rpm}, \mathrm{t} 1=3 \mathrm{~s}$.

\subsection{Hardness distribution}

The hardness distribution along the axis of the joint is shown in Fig. 8. The small diameter rod subjected to $\mathrm{N}=$ $6000 \mathrm{rpm}$ and $\mathrm{t} 1=1 \mathrm{~s}$ presented harder values at the vicinity of the friction weld interface. However, near to the weld interface, the hardness was lower when increasing the rotational speed and the friction time. Large-diameter joints (Fig. 6(b)) were softer near the interface regardless of the rotational speed, but the immediate vicinity of the weld interface had a slightly higher value than the outer area.

For the microstructure described above, the fine structure was expected to be harder close to the friction weld interface. Maximum temperature indicated lowest value at the revolution speed $6000 \mathrm{rpm}$, friction time $1 \mathrm{~s}$ of the small-diameter joint did not observe softened area of hardness. The friction weld interface showed a slightly higher hardness than at the surroundings. This indicates the effect of the temperature on the softening effects when compared to the grain refining ef-

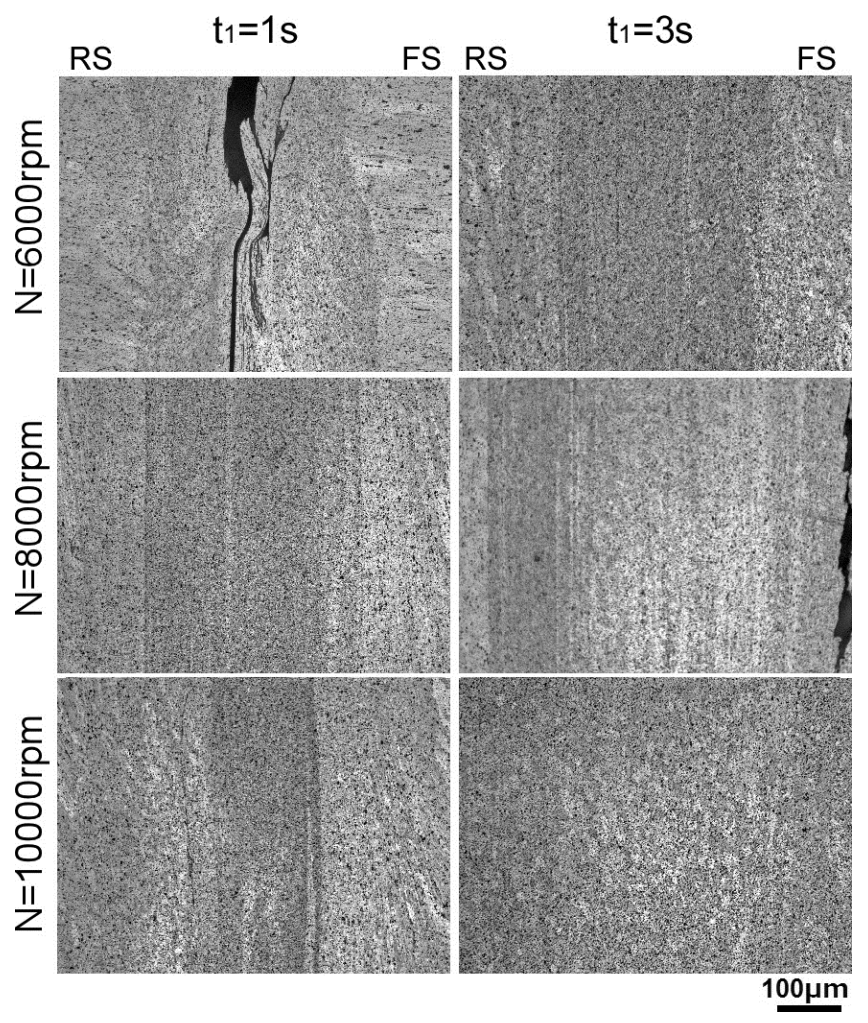

Fig. 7 Microstructures of the joint of thin $(\varphi 5 \mathrm{~mm})$ rods welded under various conditions.

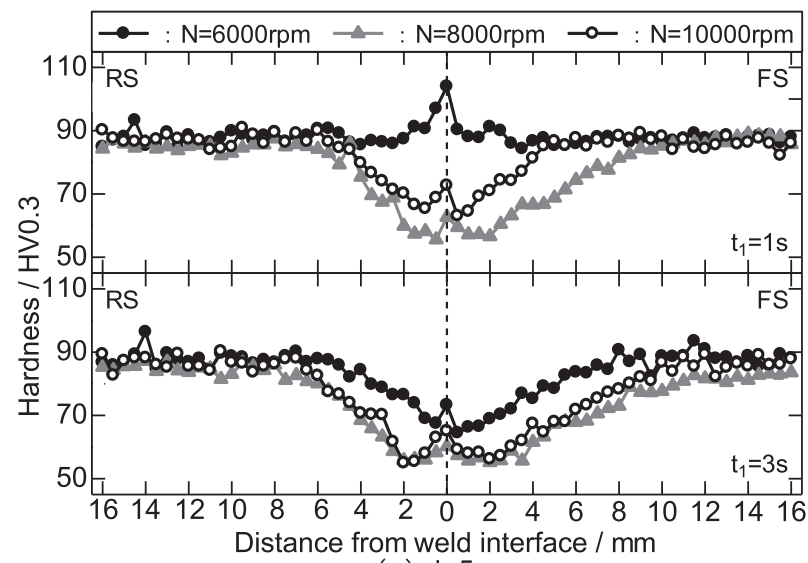

(a) $d=5 \mathrm{~mm}$

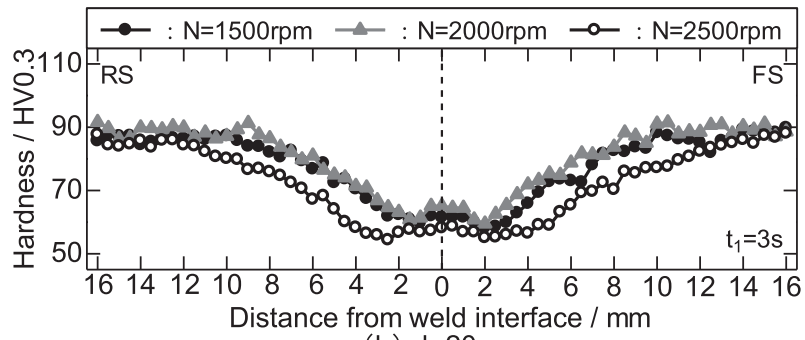

(b) $\mathrm{d}=20 \mathrm{~mm}$

Fig. 8 Hardness distributions of the joint welded under various conditions. (a) The case of thin $(\varphi 5 \mathrm{~mm})$ rods, (b) thick $(\varphi 20 \mathrm{~mm})$ rods.

fect. This phenomenon is well known as a softening effect generated in the friction-welding joint on wrought or heat treatable aluminum alloys ${ }^{12-17)}$.

Figure 9 shows the width of the softened area determined 
from the hardness distribution. The values measured at the RS and FS were represented. Although the width of the softened zone for large-diameter joints was observed with little difference in rotational speed (1500 rpm and $2000 \mathrm{rpm}$ ), it widened with a rotational speed of $2500 \mathrm{rpm}$. The width of the softened region then became wider at friction time of $3 \mathrm{~s}$ regardless of the revolution speed. The softened zone of the small-diameter joints increased with the revolution speed. This is due to the fact that small-diameter joints in the temperature measurements demonstrated large difference temperature in the axial direction. In general, the hardness distribution of symmetrical weld interfaces in both the RS and FS showed similar hardness distributions. However, FS showed some tendency to show a wider softened zone in comparison to the RS. This phenomenon is unclear because the temperature of the RS could not be measured, but on the RS, it is assumed a heat radiation caused by the air flow during the tool revolution and a heat conduction. The high revolution speed of small-diameter joints presumably increased the differences of temperature.

\subsection{Tensile test}

Figure 10 shows the results of tensile tests. The tensile strength of the small-diameter joints decreased while increasing the revolution speed for a friction-welding time of $\mathrm{t} 1=$ $3 \mathrm{~s}$. Friction-welding conditions at $\mathrm{t} 1=1 \mathrm{~s}$ and $\mathrm{t} 1=2 \mathrm{~s}$ showed the highest tensile strength with an increase in the revolution speed. The tensile strength of large-diameter joints was improved with an increase in the revolution speed. In the range

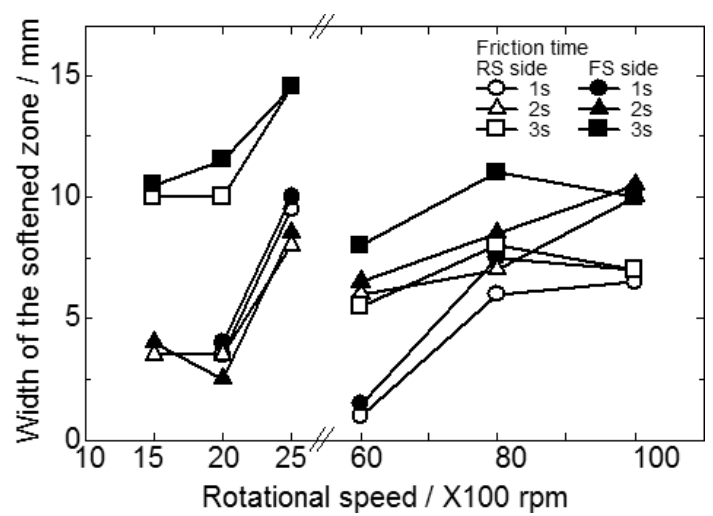

Fig. 9 Relation between rotational speed and width of the softened zone.

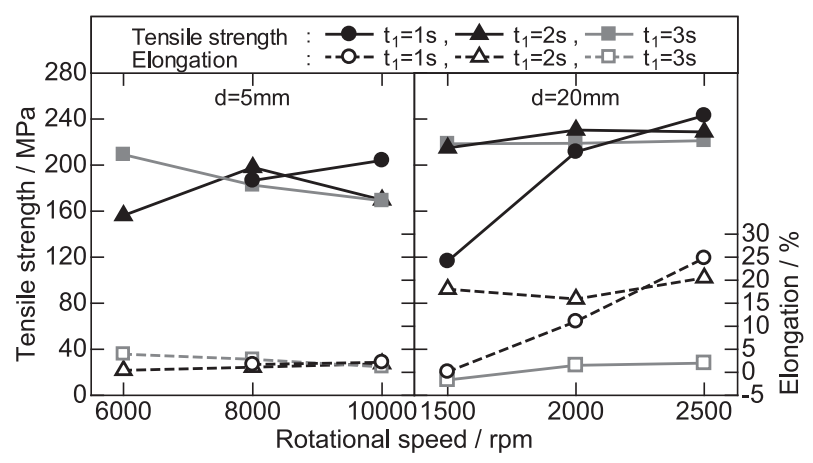

Fig. 10 Relation between rotational speed and tensile strength and elongation of the joints. of this experimental conditions $(\mathrm{N}=6000 \mathrm{rpm}, \mathrm{t} 1=3 \mathrm{~s})$, the tensile strength of small-diameter rods reached $209 \mathrm{MPa}$, which is $79 \%$ of the base material's strength. For the large-diameter joints, the obtained value was approximately $90 \%$, with an average value of $243 \mathrm{MPa}$ (in this case, $\mathrm{N}=2500 \mathrm{rpm}$ and $\mathrm{t} 1=1 \mathrm{~s}$ ). Thus, the large-diameter joints demonstrated a higher strength compared to the small-diameter joints for almost all welding conditions.

Concerning the elongation, the results were analogous to the tensile strength trends. The elongation values of the small-diameter joints were lower than the base material under $\mathrm{N}=6000 \mathrm{rpm}$ and $\mathrm{t} 1=3 \mathrm{~s}$ conditions. The large-diameter joints showed equal or greater values compared to the base metal in all conditions. That is, the hardness distribution shown in Fig. 8, the large-diameter joints were estimated to correspond to the softened area many tensile test specimens at a parallel part. As indicated by macroscopic and microscopic structure observation, the reduction in ductility is linked to the presence of a non-uniform structure. Depending on the magnitude of the rod diameter, the large-diameter joint $(\varphi 60 \mathrm{~mm})$ were reported the change in both the tensile strength and impact strength outer circumference part and the center part depending ${ }^{18)}$, and it is reported that the mechanical properties were increased at the joining center part. The difference in this value is considered to be in the range of variation. The small-diameter joint is recognized to the inhomogeneity part at friction weld interface, but the mechanical properties were considered to be within the range of variation.

Figure 11 shows the macroscopic structures of the tensile test specimens. In the small-diameter joint shown in

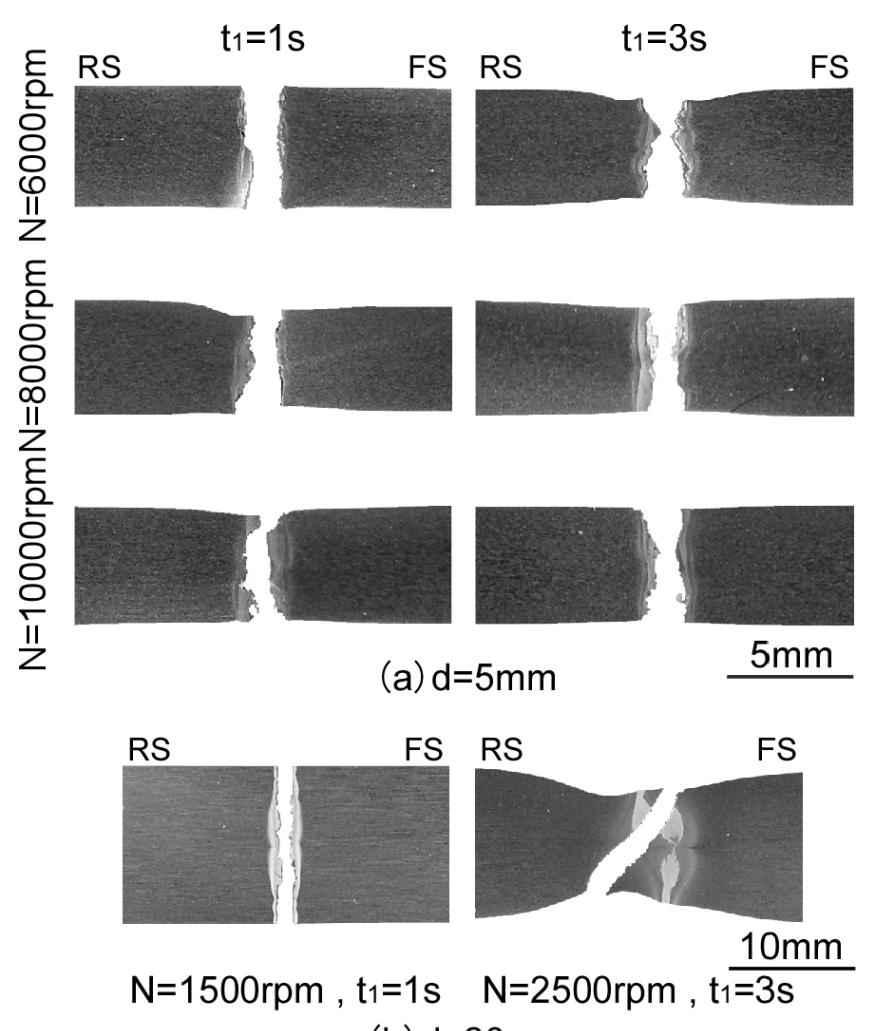

(b) $d=20 \mathrm{~mm}$

Fig. 11 Macrostructures of tensile fractured joint. 
Fig. 11(a), there is a fracture in the heat-affected zone of the weld interface regardless of the welding conditions. This fracture was perpendicular to the tensile load axis. The elongation corresponding to $\mathrm{N}=6000 \mathrm{rpm}$ and $\mathrm{t} 1=3 \mathrm{~s}$ conditions reached higher values than the base metal. A necking effect was observed under this condition. But other friction-welded conditions reduced elongation. These conditions promoted a little necking before the fracture. The large-diameter joints shown in Fig. 10(b) showed a similar fracture appearance than that of the small-diameter joints a low revolution speed. High-revolution speed joints were broken across the weld interface involving a large necking effect.

\section{Conclusion}

The friction-welded joints of small-diameter rods on A5052 aluminum alloy were studied. The influence of the macro- and microstructures on the mechanical properties, which varied depending on the friction-welding conditions, were evaluated. In addition, the differences of properties for different rod-diameter joints were considered, with the following conclusions:

(1) The macro- and microstructures obtained showed a similar appearance regardless of the rod diameter influence. However, friction-welded defects were observed in some of the conditions of the small-diameter joints.

(2) The maximum temperature at the FS of the weld interface demonstrated higher values for the large-diameter joints when being compared to the small-diameter joints. The temperature difference in the axial direction is not very high.

(3) The width of the softened zones was narrow when comparing the RS to the FS, and the difference of such softening effect was significant in small-diameter joints.

(4) The maximum tensile strength of small-diameter joints was $209 \mathrm{MPa}$, which is $79 \%$ of the base metal value. For large-diameter rods, the strength was $243 \mathrm{MPa}$ or $90 \%$ of the raw condition value. The fracture was located in the heat affected zone for the small-diameter joints. In the case of the large-diameter rods, the fracture was similar to that of a small diameter joint at low revolution speeds. However, at high revolutions, the fracture occurred near the weld interface accompanied by a large necking effect.

\section{REFERENCES}

1) S.K. Singh, K. Chattopadhyay, G. Phanikumay and P. Dutta: Acta Mater. 73 (2014) 177-185.

2) H. Tokisue and K. Katoh: JJILM 52 (2002) 378-383.

3) For example, K. Okuyama: Journal of Japan Fricdtion Joining Association 10-2 (2011) 8-13.

4) For example,M. Kimura, K. Shiragami, M. Kusaka and K. Kaizu: Transactions of the JSME 80-815 (2014), 1-16.

5) For example,M. Nomoto, K. Katoh and H. Tokisue: Journal of Japan Fricdtion Joining Association 13-1 (2014), 49-54.

6) Friction Welding: Society of Friction Welding: CORONA PUBLISHING CO.,LTD,(1979) 33-34.

7) T. Nakamura, S. Nakahara, M. Aoyagi and M. Yano: Journal of Mechanical laboratory 23 (1969) 196-208.

8) Y. Asano, Z. Arafuka, M. Nomoto and K. Katoh: The 126th Conference of Japan Institute of Light Metals, (2014), 331-332.

9) H.H. Koo and A. Baelock, III: Weld. J. 71 (1992) 147s-170s.

10) K. Ogawa, Z. Ueda, S. Kaga and H. Yamaguchi: JJILM 41 (1991) 504509.

11) H. Tokisue and K. Katoh: JJILM 28 (1978) 450-454.

12) Y. Fuwano, K. Katoh and H. Tokisue: JJILM 50 (2000) 157-161.

13) K. Katoh and H. Tokisue: Journal of Light Metal Welding 28 (1990) 16-21.

14) K. Katoh and H. Tokisue: JJILM 34 (2008) 325-330.

15) K. Ogawa, S. Ochi, T. Sawai and H. Yamaguchi: JJILM 41 (1991) 504 509.

16) Y. Yamamoto, S. Ochi, T. Sawai, H. Yamaguchi and K. Ogawa: JJILM 56 (2006) 366-370.

17) H. Takegami and T. Shinoda: JJILM 52 (2002) 580-585.

18) M. Nomoto, K. Katoh and H. Tokisue: Journal of the Japan Friction Joining Association 9-3 (2010) 12-16. 